\title{
Analyzing resilience with communicative systems theory an example from European fisheries
}

\author{
Douglas C K Wilson * and Rikke Becker Jacobsen
}

\author{
* Correspondence: dw@ifm.aau.dk \\ Innovative Fisheries Management, \\ Aalborg University Research Centre, \\ Aalborg, Denmark
}

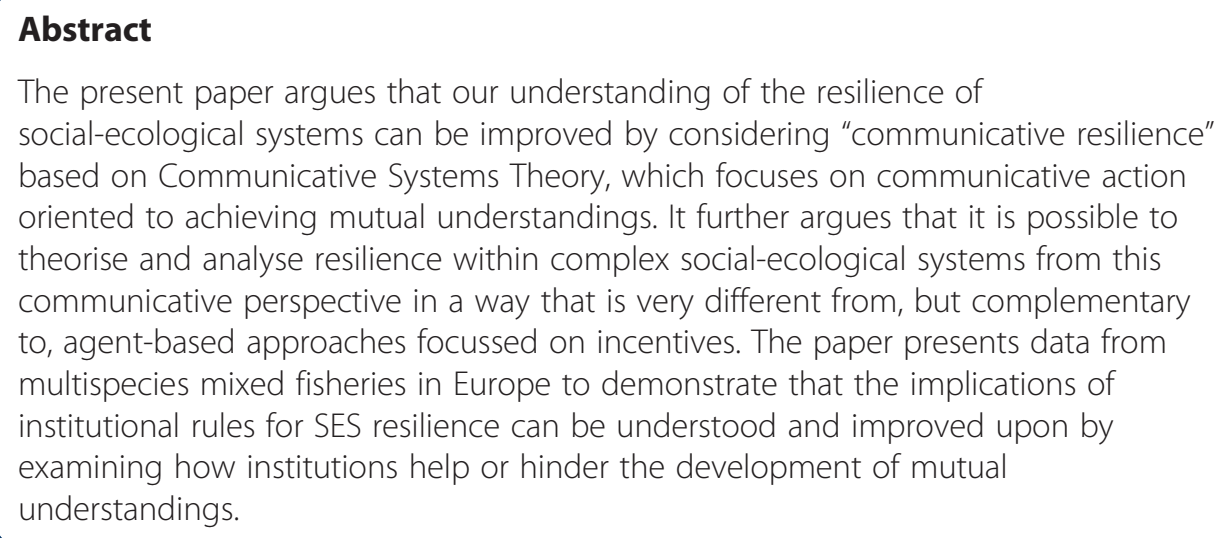

The present paper argues that our understanding of the resilience of social-ecological systems can be improved by considering "communicative resilience" based on Communicative Systems Theory, which focuses on communicative action oriented to achieving mutual understandings. It further argues that it is possible to theorise and analyse resilience within complex social-ecological systems from this communicative perspective in a way that is very different from, but complementary to, agent-based approaches focussed on incentives. The paper presents data from multispecies mixed fisheries in Europe to demonstrate that the implications of institutional rules for SES resilience can be understood and improved upon by examining how institutions help or hinder the development of mutual understandings.

\section{Introduction}

In recent years there have been a number of exciting theoretical developments around the idea of the resilience of social-ecological systems (SES). Many are inspired by theories of complex adaptive systems in both natural science and economics (for instance Holland 1992; Miller and Page 2007). Using agent-based approaches they illuminate SES by analysing the relationships between institutions, the strategies that emerge from the incentives and norms of agents, and ecological systems (Folke 2006; Ostrom 2005, 2007). However, while resilience theorists recognizes the importance of the characteristics of communication, especially in the form of collective learning (Armitage 2005; Folke 2006; Wilson 2002) systematically theorized communicative approaches in resilience thinking are lacking; a major reason being the difficulty of developing such approaches within an agent-based framework.

This paper helps address this lack by examining science-policy "boundary objects" using Habermas' (1987) communicative systems theory (CST). We suggest that "communicative resilience" is an essential part of "social-ecological resilience". We illustrate the approach through a discussion of one complex type of SES: multi-species, mixed fisheries (MSMF). The paper begins with a description of the MSMF problem, then outlines the theoretical approach, and finally describes research based on communicative resilience that examines two types of boundary objects that have been important in MSMF in Europe. The conclusion suggests communicative resilience can be improved by not trying to reduce discussions of complex systems to simple categories designed for institutional convenience. 


\section{Multispecies mixed fisheries as complex socio-ecological systems}

A multispecies fishery refers to fisheries where more than one species is vulnerable to being caught. In many cases a multispecies fishery is also a mixed fishery, meaning that more than one combination of fishing vessels and gears are being used. Mixed fisheries generally involve four major kinds of actors. The fishing industry is very diverse but generally holds maintaining long-term sustainability as a strategic goal while facing short-term pressure to cover operating costs. Conservation ENGOs wish to protect marine environments, biodiversity and sustainability. To some degree managers' incentives match both of the other main groups when it comes to conservation objectives; they are interested in both profits and sustainability and, sometimes biodiversity. Scientists are called upon to provide advice on ecological conditions on which policies will be built.

MSMF are managed by a varied array of measures. The two most basic approaches are 'input' control over the amount and type of fishing activities and 'output' control over the amount of fish caught. In Europe the two main systems for implementing these are referred to respectively as 'effort management' and 'quota management'. Effort management makes it hard to transparently divide fishing opportunities among fishers or countries. Fishers also quickly find ways to catch more fish with a given effort, a problem called 'effort creep'. However, effort management has weaker incentives for discarding unwanted fish because a vessel may land whatever fish it catches in its allotted time. Effort is also not necessarily applied to a specific fish stock and this simplifies scientific monitoring and estimations of fish abundance.

Quotas are an amount of fish, so they are easily divisible and the relationship between quotas and catches is in principle direct. Quotas, however, are based on a total allowable catch (TAC) that must be defined based on a fairly precise estimate of how many fish are available to be sustainably caught from a particular stock. These estimates can be especially difficult in MSMF because of biological interactions among species and the data complexities that arise from having many different fleets and gears catching fish. All quota systems face problems with discarding fish, for example to bring higher quality fish to market. In MSMF an important driver of discarding is catching fish that a fisher does not have a quota for or that is otherwise protected. Discarding also creates data problems because discarded fish are not recorded. Quota management has historically been based on a common pool quota given to a fishing fleet, but more recently granting an individual quota (IQ) to fishers has become popular. These systems eliminate economically inefficient and dangerous practices such as racing to fish a common quota. When made freely transferable (ITQ) the market will allocate fish with the highest economic efficiency among management alternatives (Hannesson, 2004).

MSMF management has evolved in complex ways. In Japan the strategy selected was to control effort, through reductions in licenses, shortening seasons and imposing closures. The emphasis was on the simplicity and effectiveness of these measures compared to a quota system within a large coastal fishery (Nagaski and Chikuni, 1989). Effort creep nullified the effectiveness of the input controls (Yagi 2001) so a quota system was introduced for several major species in 1997. Managers were still concerned about the scientific accuracy needed for a quota system, and an effort approach was retained for some stocks. The New England groundfish fishery in the USA experienced serious decline in important stocks as early as the 1960's. The first generation of measures combined input and output control, introducing catch quotas, minimum fish size, 
minimum mesh size and seasonal closures of spawning areas and later individual trip limits. Direct limitations on both catch and fishing effort came in 1994-1995 with a range of new measures including individual stock TACs for five stocks and an aggregated TAC for seven others. Recently sector management has been introduced. This involves self-organising groups of fishers who enter into a contractual relationship with management in which they develop their own plans to fish sustainably for a total allowable catch based roughly on their individual histories. These contracts then excuse them from some other restrictions, including the days-at-sea effort control system.

Countries using ITQ systems have addressed the discarding problem in several ways, all of them complex and multilayered. In Canada vessels are required to have a quota for any species they might catch and discarding is banned with some few exceptions. The larger vessels carry observers on board but discarding remains a problem on smaller vessels (Rescan and Wilson 2009) because fishers find it easier to dump than to go through the complex system of trading for the quota they would need to legalise their catch (Caddy \& Agnew 2004). In Canada and New Zealand temporary closures of areas with high discards are used to back up the discard ban. This measure has led to more selective fishing (Branch and Hilborn 2008), as fishers seek to avoid the automatic closures resulting from an exhausted cod quota (Caddy \& Agnew 2004). New, inexpensive surveillance technologies are increasingly being used to monitor fishing activities at sea.

Sanchirico et al. (2005) review how ITQ systems in MSMF in five countries have addressed the general problem of balancing catches with allocated quotas. The key is to give fishers the flexibility to work within the system. They found that it was helpful to have multiple instruments in place to give fishers different ways to match quotas and catches. All the systems required ongoing changes and elaboration in response to ecological and economic conditions (Sanchirico et al. 2005). In addition to effort and quota control, management also makes use of myriad technical measures and protected areas. ITQ systems help address the allocation problem, but systems based on strong property rights are also problematic from the viewpoint of cumulative effects because they are a poor fit with measures that decrease the value of quotas. Murray et al. (2010) argue that the relentless accumulation of management measures brings about a loss of flexibility and the erosion of community.

\section{Theoretical approach}

Resilience thinking is rooted ideas about complex adaptive systems (Holland 1992) first developed in ecology. Berkes et al. (2003) suggest that resilience has been defined two basic ways in ecology. The first defined resilience as the ability to return to this steady state. More recently the focus has been on how a once stable ecological regime, i.e. a particular structure of ecological processes, can change into a new stable regime. Resilience is defined as the magnitude of the disturbance needed for such a change. They, along with others (Folke 2006; Gunderson and Holling 2002; Low et al. 2003) emphasize that resilience thinking is a step away from an equilibrium concept of systems towards one that assumes change and seeks to explain stability. Redundancy, homogeneity, diversity and adaptability are commonly associated concepts as in, for example, Folke's (2006) argument that poor management results in reduced resilience when landscapes become homogenized and more vulnerable to disturbances. 
Social resilience is a much less developed concept with very general definitions, such as Adger's (2000) "the ability of groups or communities to cope with external stresses and disturbances as a result of social, political and environmental change" (347) being common. Too often theorizing social resilience has been muddied by analogies from natural ecology (Wilson 2010). Capacity for adaptive social learning is perhaps clearest dimension of social resilience found in the literature and great emphasis is placed on it by Armitage (2005), Berkes et al. (2003), Gunderson and Holling (2002), Hahn et al. (2006), and Wilson (2002) among many others.

By seeing society and its material basis as a set of interconnected systems ecological and social resilience can be thought of as aspects of SES resilience. Both kinds of resilience depend on one another, but one cannot assume that one guarantees the other (Folke 2006). Folke (2006:259) cites Carpenter et al. 2001 in respect to three core ideas within SES resilience: "(1) the amount of disturbance a system can absorb and still remain within the same state or domain of attraction, (2) the degree to which the system is capable of self organization (versus lack of organization, or organization forced by external factors), and (3) the degree to which the system can build and increase the capacity for learning and adaptation. "Central to the argument in this paper is the idea that adaptive processes result from a system's self organization (Folke 2006, Norberg and Cumming, 2008) and, hence, "the concept of resilience in relation to social-ecological systems incorporates the idea of adaptation, learning and selforganization in addition to the general ability to persist disturbance" (Folke 2006:259).

Using a version of CST inspired by Habermas (1987; 1991), and further developed elsewhere (Wilson and Jentoft, 1998; Wilson 2003, 2009a), we offer the concept of "communicative resilience" as the part of the resilience of SES that makes adaptive social learning possible. We define communicative resilience as the degree to which people within an SES are able to express themselves by drawing on the full range of background understandings that allow communication to be meaningful. We argue that many institutions, i.e. the shared cognitive, normative and regulative understandings that maintain stable patterns of social interaction (Wilson and Jentoft, 1998), systematically restrict such expression. These restrictions can and do inhibit social learning by blocking the criticism and/or contextualization of understandings of the social or ecological environment.

If any institution is going to maintain a stable pattern of behaviour it must simultaneously coordinate two often contradictory kinds of interaction: strategic action in pursuit of actors' objectives and communicative action for developing mutual understandings of situations. "Mutual understanding" is not agreement; it means that participants' perceptions of a situation are close enough for responsive interaction to occur. Agent-based theories of institutions, while recognising the importance of communication, conceptualise it as one more strategic resource available to the agent (Ostrom 2005). For example, Ostrom et al. (1994:33) consider 'the way actors acquire process, retain, and use knowledge, contingencies and information' to be one of four key characteristics of an actor. CST, in contrast, focuses on the conditions of communication at the institutional level.

CST considers communication through the contrasting logics of the $2^{\text {nd }}$ person (you and I communicate with each other) and $3^{\text {rd }}$ person (I/you/he/she observe a system of communications) perspectives. The "mutual" in "mutual understanding" 
depends on the $2^{\text {nd }}$ person communication and begins with the standards of "rational communication". Habermas' famous ideal speech situation, that there is "no manipulation involved in the communication; and that everything communicated is open to question about its validity" (White 1988, 56), expresses such standards. The power of these counterfactual ideals derives from the fact that during $2^{\text {nd }}$ person interaction we use them to evaluate communicative actions. Mutual understandings, even in situations of differential power, require an element of persuasion. Your boss can tell you what to say and do but he or she must persuade you to think something is actually true. These standards guard access to what Habermas calls the "lifeworld", the background of shared meanings language, culture, socialization - that make communication possible.

Rational communication also requires that claims be oriented toward types of mutual understandings. For example, a claim of fact is oriented toward consensus about its truth; a claim of value is oriented towards an agreement about the rightness of its general applicability, and a claim of interest is oriented towards possible compromise. These orientations are background assumptions in communication that help us make sense of what is being said. An illustration is that if someone says "let's just split the difference" in respect to interests this makes perfect sense, but saying the same thing in respect to facts is at best an admission that the facts are unknown.

The $3^{\text {rd }}$ person perspective is utterly different. From this perspective we begin with the question of strategy. When we observe the communicative system from the $3^{\text {rd }}$ person we often see persuasion as a veneer over manipulation or draw attention to how the voices of the powerless have been silenced. As social scientists seeking to understand a discourse we look at how people link facts, values and interests, not at how they keep them rationally separate. It is this huge difference between the logic of the $2^{\text {nd }}$ and $3^{\text {rd }}$ person perspectives that is the heart of CST.

To relate these two perspectives CST takes an entirely different angle from agentbased approaches and describes social systems in communicative terms. The $3^{\text {rd }}$ person view of mutual understanding begins by observing the social-psychology of building and reproducing institutions at the small group level. We account to each other for what we do and say and these accounts iteratively reproduce patterned social interaction. Scott and Lyman (1968:46) tell us that accounts 'shore up the timbers of fractured sociation' and observe that ways of accounting for behaviour become routine within subcultures and groups. The ethnomethodologists showed through repeated observation and experiments that norms and rules do not so much provide a cookbook for action as the language of accounting for behaviour after the fact (Heritage 1984). Weick (2001) describes how organizations faced with new situations act first and make sense out of their actions later. Competing accounts of reality are the material of strategic action in the communicatively conceived social system.

CST develops the systemic aspects of the $3^{\text {rd }}$ person perspective through the idea of "generalized communications" which reconceptualises as mechanisms of communications those dynamics most closely associated with social power. Prestige and influence are generalized communications that contribute to mutual understanding through preunderstandings about whose voices will carry the most weight. They operated in highly lifeworld-dependent institutions such as science or communities. Markets, private bureaucracies, and governments, however, make heavy use of money and authority, ${ }^{a}$ generalized communications that Habermas (1987) calls "steering media". Money and 
authority create mutual understandings while shortcutting communications dependent on the lifeworld. Steering media do this in a mechanical and automatic fashion facilitated by a nearly complete marginalization of the lifeworld. Authority requires access to the lifeworld only to create an understanding of to the content of the order, the related sanction and the recognition of a condition that triggers the order's application. One can use money to buy a soda in a place where one knows nothing of the language or culture, the needed mutual understanding is automatically provided. Steering media are critical to institutions that operate on higher scale levels and/or require more predictable outcomes. For steering media to operate some form of coercion or pressure must be in place to replace the persuasion that the vastly reduced access to the lifeworld makes no longer possible. This coercion must refer to some objective reality. For example you cannot get the soda without paying, and the existence of the soda must also be verified. More relevant to the discussion at hand, authority requires a verifiable, legal "rule condition" (Ostrom 2005), to support its ability to replace the richer communications lifeworld access makes possible.

In institutions where steering media are the primary mechanisms of communication, accounting becomes formal accountability focussed on these objective realities. The contrast of the two perspectives is important here. What we call "objectivity" from the $3^{\text {rd }}$ person is the same condition of sanctioned reality that we refer to as "transparency" from the $2^{\text {nd }}$ person. The scientific method that we rely on to produce objective facts is nothing but a set of procedures for making knowledge as transparent, i.e. as verifiable by the community at large, as possible (Wilson 2009a). Accountability is not possible without this dual condition. To hold people accountable we must see what they have done. This duality means that accountability acts as a sort of lubricant between the often contradictory goals of strategic actions in pursuit of interests and communicative actions in pursuit of mutual understandings. If certain fish stocks are to be avoided in an MSMF what is required is both a commitment by the fishers to selective fishing and evidence that selective fishing actually taking place, without both of these in place the attempt to create a new pattern of behaviour will grind to a halt.

Within environmental management these objective realities are increasingly 'boundary objects'. Boundary objects are such things as models, indicators, environmental action plans and joint research products that focus discussions across the boundary of science and policy (Cash et al. 2002). In complex SES, developing mechanisms for accountability almost always involves science because of the complexity of human activities and of monitoring their impacts on ecosystems. When a boundary object is working it pulls together concepts that are acceptable to the various parties involved in its development. In complex SES, the elements of institutional grammar that Ostrom calls "conditions," are often boundary objects. Conditions are the "variables that define when and where an institutional statement applies' (2005:149). From the CST perspective these are the objective referents that authority depends on to shortcut the lifeworld.

The need for objective rule conditions means that institutional imperatives heavily sway the content of boundary objects often resulting in less access to the lifeworld for both scientists and stakeholders seeking to raise questions. This is because in complex SESs, environmental managers often seek boundary objects that give simple messages with little nuanced content even when the science is complex and/or uncertain. An 
example is the setting of TACs. ICES scientists very frequently deal with uncertainties by inserting rich textual explanations of data and analysis below the tables where TACs are reported, but the European Commission has no good way to use this textual information and so must simply adopt the reported number (Wilson 2009a). Rule conditions have to be created even under conditions of complexity and uncertainty. The threat is that, once in place, a rule condition can be reified into a new "objectivity" that stands beyond effective contextualizing, questioning or explaining and hence is not objective because it is not transparent. Rule conditions anchor a steering medium that works by marginalizing the lifeworld, i.e., the same communicative resources that are needed to generate the critiques, nuances and caveats that allow a rich reflection of the realities in the social and natural environment. Institutions that are crucial to the resilience of SES are grounded by science/policy boundary objects that are used to literally truncate meaning itself - including meaning needed for accurate science. No institution is more dependent on full lifeworld access than science. Theories rooted in a $3^{\text {rd }}$ person perspective have noted the creation of scientific "black boxes" but have depicted them as the result of strategic interactions (e.g. Latour 1987), something that can only illuminate aspects of the particular forms the boundary objects take. From the $2^{\text {nd }}$ person perspective within CST it is the shortcutting of the lifeworld that seals the box around science/policy boundary objects.

CST's $2^{\text {nd }}$ person perspective opens up the possibility of the amelioration of these problems through institutional design. This is what communicative resilience adds to the overall resilience of SESs. The mixture of generalized and rational communications found in institutions is variable and can be changed by design. More rational communications allows the communication of richer and more nuanced pictures of both ecological and social situations. It is the foundation of social learning, the self-organization and adaptation of social institutions.

Once understood, CST is a coherent description of social reality, it is rooted in everyday experience and some of its tenants have survived systematic tests (Wilson 1998). However, if communicative resilience based in CST is going to be useful for diagnosing problems and informing institutional design then it must offer a methodological approach rooted in the $2^{\text {nd }}$ person, $3^{\text {rd }}$ person distinction that is central to the theory.

Standard social science methods can be used to alternate between the perspectives to build up a picture of the central diagnostic question: the impact the $3^{\text {rd }}$ person communicative system is having on the $2^{\text {nd }}$ person lifeworld. Qualitative, in-depth interviews and focus groups, when correctly carried out, straddle the $2^{\text {nd }}$ and $3^{\text {rd }}$ person. The interviewer, who is seeking to understand the subjective experience of the respondent, listens and questions while evaluating statements through the screen of rational communications. But the discussion itself is oriented to the $3^{\text {rd }}$ person because what is being asked is a description of the SES of interest. This output is subjected to a discourse analysis; a $3^{\text {rd }}$ person exercise that maps the way facts, interests, and values are linked in discursive themes while trying to minimize the question of the validity of the claims being made. Then institutional factors that are blocking claims people wish to make can be identified. The first case study below of an MSMF boundary object stops at this point.

However, as the second case below demonstrates, quantitative methods used to understand the subjective viewpoints of respondents through various sorting exercises 
(Brown, 1980; Coxon, 1999) can contribute as a further iteration that clarifies the relationship between the two perspectives by rendering respondents' $2^{\text {nd }}$ person perspectives into comparable forms. The elements being sorted are usually statements of facts or value but they can also be physical or natural objects. They must emerge from the discourse analysis and not from some a priori theory. Kapasa et al. (2005), for example, using Q sorts and consensus analysis, show that Zambian fishers who use a type of gear that, without scientific confirmation, is considered "destructive" tend to have both the highest levels of local ecological knowledge and are the most likely to hold opinions that are contrary to a strong consensus agreeing with the ecological opinions and policies of the local Department of Fisheries. Their use of illegal gear, however, blocks their full participation in the local fisheries co-management programme. In another example Wilson (2010) combines agreement with statement sets and social network analysis. The degree to which pairs of respondents agree with each other about science while disagreeing about policy is used as a measure of rational communication. The analysis found that the only network pairs having higher agreement on science than policy were fellow members of a fisheries co-management committee.

The boundary objects case studies that follow seek to apply CST through this same set of methods.

\section{Boundary objects in European multispecies mixed fisheries}

This section draws on field data to explore two kinds of boundary objects in European MSMF. The two are nearly opposites in terms of the role played by the boundary objects in the creation of rule conditions. Recovery plans for depleted stocks are sets of various legal acts and their discussion as observed here rarely touched on specific rules. The definitions of fisheries and fleets, however, are directly used as the basis of both scientific models and management rules. The field data comes from the observation of nine working groups of European fisheries scientists and three meetings of Regional Advisory Council (RAC) working groups. RACs are stakeholder fora on which both the fishing industry and conservation ENGOs sit. The three RACs included here are the North Sea, Baltic and Southwest Waters RAC. The RACs' remit is to provide advice on fisheries management to the European Commission's Directorate General for Marine Affairs and Fisheries (DGMARE). In addition to observing meetings, interviews were also carried out with fishers in 12 fishing ports, six fisheries scientists, five government fisheries managers and three focus groups. All of these were in-depth, open ended interviews. The port interviews also included a pile sorting exercise to see how fishers classify vessels. Information from a short email questionnaire done with twelve RAC members is also used.

\section{Recovery and long-term management plans}

This set of boundary objects involves scientists, managers, conservation ENGOs and the fishing industry. The first recovery plan began in February 2001. Initially they were sets of emergency measures, but general guidelines came in 2004. While individual measures are legally enacted, recovery plans are not a single legal act. A general stakeholder consensus supports the plans. However, this shared ideal of seeking the recovery of a stock leaves many issues of disagreement in the details. In spite of these differences in details and emphasis, even this broad, symbolic consensus has proven important 
because it has allowed stakeholders with conflicting interests to develop a cooperative agenda, especially in the RACs (Wilson 2009b).

The following is from a public talk by the Director of Conversation Policy at DGMARE early in the process of recovery plan development. The focus is on the scientific input into the process of developing recovery plans:

Q1. What do we need for such recovery plans? As they will normally contain targets for recovery or long-term management, usually expressed in terms of biomass, we need clear precautionary and limit reference levels for the stocks concerned. They will also contain harvest rules; that is rules for the fixing of TACs over several years ... [later in the document]. It means a concentration of resources, at least in the short term, on the analysis of the most depleted fish stocks (Farnell 2003).

For DGMARE recovery plans are strategic mechanisms that are used to concentrate fisheries management capacity on a subset of the most serious problems with depleted stocks. There is an emphasis on biomass targets and the precautionary approach (PA).

Two central questions about the recovery plans are their relationship to long-term management plans (LTMPs) and effort management. Q2 presupposes a rather smooth movement from recovery plans to long-term management plans (LTMP) based on harvest control rules (HCRs). These are rules in a form 'for Y condition X change in harvesting pressure is required' and are one of the aspects of LTMPs that all stakeholders see as useful for differing reasons. The following is unequivocal about LTMPs while being more circumspect about effort management:

Q2. Interviewer: So, you see the recovery plans as sort of a starting point for a general reform, a general move towards effort management and long-term management? Commission Administrator: Certainly to long-term management; to effort management in justified cases. I think it's clear there won't be a general signing up to effort management as the normal, or as a normal instrument for fisheries management, but I think there is recognition that we will need to manage effort in order to make particular efforts to stop the serious degradation of the stock collapses.

The movement from recovery plans to more general long-term planning is a priority for the fishing industry. The following is from a member of an industry RAC member:

Q3. [LTMPs] remove political interference in the process of setting allowable catches by removing the ability of Member States to question the output given that the plan would have been agreed through Council. The output is clinical and precautionary thus affording greater security to the stocks.

Recovery plans are to be driven by technical considerations through HCRs. For the industry an important aspect of this is reducing uncertainty in business planning and stability of supply.

Some members of the industry see positive outcomes from the recovery plans because they provide a way of contributing their knowledge about technical conservation 
methods, selective fishing, and closed areas and gave individual fishers a way to benefit from responsible fishing. However, both the industry and the ENGOS were engaged late in the process. A RAC staffer described them as "sprung upon" the industry based on an "ICES philosophy". The International Council for the Exploration of the Sea (ICES) is an independent multilateral organisation. It produces the official scientific advice for fish stocks in the northeast Atlantic and adjacent seas and DGMARE is its biggest client. Recovery plans were initially developed by DGMARE and ICES and then presented for comment. In the development of science - policy boundary objects scientists are not seen as simply neutral facilitators no matter how hard they may try to keep their role as doing science but not management. The failure to involve stakeholders early limited the range of their responses. For one thing, the plans were already based on individual fish stocks as their basic unit, while the industry wanted this unit to be fisheries and the ENGOS wanted a more ecosystem-based perspective. A RAC staff member:

Q4. We had a really important meeting where we laid down our ideas for long-term management plans, and the most important thing that came out of that was that it was the fisheries that the plans ought to relate to, not the stocks. Now, that's been diluted since, whenever we discuss management plans with the Commission they still try to refer to stocks.

Of course, many fishers simply do not agree with the recovery plans. The industry sees both scientists and managers as interpreting the precautionary approach too narrowly in the development of the plans. Many in the industry felt that if they had been included earlier in the process then the objectives would have been more realistic. They echoed the classic MSMF complaint about protecting one threatened stock by limiting access to all the others:

Q5. Industry RAC Representative: Opportunities to take other species in a mixed fishery are lost when a so called recovery stock is taken. The abundance of cod makes it almost impossible for cod to be avoided and thereby additional days to catch other species are lost.

Conservationists also strongly support the move towards a longer term approach. One conservationist RAC Member argued that the LTMPs being developed are improving under adaptive management and developing them for all stocks should be a priority. Conservationists are also link the recovery plans to a more ecosystem-based approach to management.

Q6. Conservationist RAC Member: It appears that a requirement to protect/restore ecosystem functioning is missing from the current application, and this must be incorporated into processes in the future, if recovery is to be successful.

Perhaps the greatest challenge the Commission faces as it tries to develop recovery plans is that, particularly in their long-term aspects, these plans are not a clean fit with official EU fisheries decision-making. The actual legal decisions are made year-by-year 
by the Council of Ministers, who have been reluctant to bind themselves to the details of long-term plans. ' This includes the kinds of if 'X condition then Y action' HCRs that would avoid short-term political decision-making.

The discourse analysis on recovery plans reveals a number of ways that access to the lifeworld was enhanced or reduced by institutional factors. The legal complexity and ambiguity allowed the stakeholders to discuss the plans while avoiding conflicts over specific rule conditions. This meant that the emerging RACs were able to use recovery plans as a critical part of inventing themselves as stakeholder fora that attracted ongoing participation from the fishing industry and ENGOS and meaningful attention from the Commission. Other institutional factors limited lifeworld access. The exclusion of the industry and ENGOs from the early development of the recovery plans limited the issues they were able to raise effectively when they did get involved. The premising of the recovery plans on individual fish stocks led to the definition of the MSMF problem as simply an expanded single species management issue. This made it difficult for the ENGOs to draw effective attention to taking a more ecosystem based approach to the problem and for the both the ENGOS and the industry to effectively point out the limitations of basing management on single stocks.

\section{Fisheries and fleets}

A fishery is an amalgam of fish stocks, fishing gears, fishing fleets and métiers; where 'fleet' usually refers to geography and vessel size, 'métier' is a term of art for sections of fleets with similar gears and fishing patterns. DGMARE's Data Collection Framework (DCF) defines métiers according to gear classes (e.g. trawls, dredges), gear groups (e.g. bottom trawls, pelagic trawls), gear types (e.g. bottom otter trawl, bottom pair trawl), main target species, and net mesh size or other selective devices (Ulrich et al. 2012). Attempts at effort management beginning in 2003 for cod used days at sea limits that ignored the DCF and defined métiers in terms of gear type and mesh size. Reforms in 2009, responding to protests from fishers, led to categories at the level of the Member States over broader gear/mesh size categories, thus allowing for more flexibility, at least for national fisheries managers (Ulrich et al. 2012). Vessel size and vessel power are also common bases for regulation, especially in effort management. These categories are used as the basis of both science and regulation, defining vessels' access rights to the fishery.

\section{Discourse analysis}

DGMARE must allocate fish among Member States. In MSMFs this means considering all the different fleets that fish for part of a stock either directly as a target species or indirectly as bycatch. To try to arrive at an objective way to address this problem DGMARE turned to the fisheries scientists:

Q7. Commission Fisheries Scientist: We want to reduce fishing mortality for cod.... The approach is to break down of the data from each of the fleets, to separate out catches of each of the species. Look at the activity of the fleet and then use a sort of optimisation technique where you put a score on the outcome that you want to have.

DGMARE is looking for a solution that 'optimises' the distribution of fishing quota and effort allocations among the various fleets. The optimisation would 
provide objective rule conditions for fish allocation decisions among the Member States. For example, scientists were asked to develop such an optimisation model for the 20-odd fleets and 60-odd métiers that fish for cod in the North Sea. This optimisation (Q7) requires precise data on what the fleets are catching (Ulrich et al. 2012). At the time of these discussions ICES' position was that the NS cod stock could not take any fishing pressure and, citing data problems for this complex array of fleets, they were unable to provide DGMARE with advice about how to fish for other stocks without damaging the cod further (ICES 2003). This reluctance on ICES' part was not well received. A high-level fisheries manager for a Member State, in fact, suggested that if ICES would not develop this advice they needed to find scientists who would.

The North Sea RAC also defines 'fisheries' in order to develop LTMPs. The fisheries they define bear no resemblance to those the defined by the DCF or the allocation models.

Q8. Interviewer: Is defining a fishery a problem? RAC Staff Member: We didn't find it difficult; actually we defined the five key fisheries for the North Sea without any difficulty at all. ... Interviewer: How does this relate to the fleet definitions, that the Commission uses. RAC Staff Member: Not at all, I mean, we simply, I think sat down at an executive committee meeting or working group meeting and said: You know, what the key fisheries that we need to have management plans for, so we, we re-invented the wheel in that respect, it didn't relate to gear type at all. Interviewer: Didn't at all? RAC Staff Member: No. Interviewer: So, did the RAC see there is a problem that all data gathering is based on a different system? RAC Staff Member: I think it didn't specifically, didn't have its attention specifically drawn to that particular problem.

Stakeholder recognize that definitions are necessary for both promulgating and analysing the impacts of management measures, especially as they would like fisheries, albeit much more broadly defined, to be the units of management. However, the definitions of fleets and métiers used in management are driven by bureaucratic needs for allocation and data collection rather than by the realities of fishing itself. The imposition of regulations on a class of vessels makes it much more difficult for a vessel to shift to another class.

This kind of flexibility was often an issue that came up when we were discussing the categorisation of boats for management in the fishing ports. Most fishers preferred categories that were large enough to allow seasonal flexibility. A member of a local fishers' organisation in Denmark told us:

Q9. It is self-evident that if you have to operate with those "days at sea", you have to say that the rules cannot be the same for a trawler and a net boat. Of course they cannot be the same. But once you've been put into boxes, it is just so difficult to come and say 'I would actually like to try and do something different from what I used to do'. You cannot do that. It's over. If you have not been in Kattegat fishing, then you will never come into Kattegat fishing.

Another challenge in elaborating this kind of boundary object is that fishers' behaviour, and hence the definitions of fleets and métiers do not remain static. This 
becomes more of a problem as the definitions become more detailed and specific. Nor are stocks and fisheries independent categories. A French fisher:

Q10. Here, it is a bit difficult. The métier we do is a function of the fish that pass by this area. So one year you are going to fish sea bream and there are years when you will catch hake and other years when you will catch whiting. It is never the same. One cannot define from one year to another what métier we are going to do, how many fish we are going to catch.

In Scotland in the 1960's and 1970's there was an explosion in multipurpose boats, and the fishers would shift according to season. But these days more and more boats stay with one kind of fishery instead of shifting according to season. The following quote from a Scottish fisher demonstrates how this is a progressive process as different kinds of management measures interact with one another:

Q11. In 1999 the boat that I had sunk and I was, it was a sort of crossroad what we were going to do. I had to build a new boat, and I built the new boat looking at what I was entitled to catch, what was the best, most efficient way to catch my quota, and that's what I came up with. So we are getting more and more, the groups are getting more and more polarised as time goes by, getting more and more difficult to jump. If I were to say later that I want to catch langoustine, that's a sort of no go. If I say I'd better go catch langoustines, I would then have to look at ways for me to exchange my demersal quota for a langoustine quota, and then I would have the expenses of making my boat capable of pursuing that split. So when it gets at it, I may not bother.

Some argue that this growing focus of the industry on particular species has reduced the ecological resilience of the fisheries system by making it difficult for fishers to fish for one species when another becomes less valuable or more difficult to catch:

Q12. Industry RAC Member: For bureaucratic, management and control reasons there has, over the years, been a move towards single species fisheries. However, this reduces the resilience of the fishing industry as the flexibility to change target species, gear et cetera in response to stock depletion or changing markets is removed. It is important not to define the fleets and fisheries into artificial categories that are either unnecessarily restrictive or devoid of meaning.

While fishers will argue that fishing flexibility provides ecological benefit, conservationists argue that it makes monitoring and controlling of fishing behaviour that much harder. They are more sympathetic to the industry view when it is part of a broader shift towards an ecosystem approach:

Q13. Conservation NGO RAC Member: I am an advocate of the ecosystem approach - which I believe needs to be integrated into the recovery plans if they are to deliver. The plan should allow, if that's what the industry requires to be viable, the option to switch between fisheries, provided that the overall take of all species and individual species is within the limits determined by scientific assessments. 
Not all RAC stakeholders agree that defining fisheries and fleets is even a requirement. Indeed, this same advocate of the ecosystem approach believes that if we did put effective limits on the overall take the general knowledge already held about fishing activities would be sufficient.

Defining fisheries and fleets is contentious because these definitions are critical components of boundary objects used as rule conditions. The process limited lifeworld access for all stakeholders. Defining fisheries for highly complex optimization models demanded that ICES scientists provide advice that they were reluctant to and sometimes refused to offer. This involved institutional pressure great enough so one manager expressed a wish for other, more cooperative, advice givers. ${ }^{c}$ This same approach to fisheries definitions undercuts the ENGOs ability to raise ecosystem issues effectively. Fishers, both their representatives on the RACs and skippers in ports, have a much more complex idea of fisheries than are reflected in either modelling or regulations but have no way effectively to include them in discussions where more official definitions are already established in monitoring, allocation modelling and regulations. These issues were further clarified using the pile sorts.

\section{Pile sorts}

A pile sorting exercise was carried out in all 12 fishing ports (Jacobsen et al. 2009). Fishers were given the names of local vessels on cards, asked to place them in piles of similar boats "in any way that makes sense", and then asked to explain how they made their category choices. These pile sorts were then used as the basis of a cluster analysis in order to report general results. Every port used fishing technique, which loosely corresponds to the DCF's "gear group" and boat size as important criteria. All of the main regulatory and data gathering categories appear in some form in the fishers' categories except for mesh size.

The great difference is that fishers recognize many more dimensions than the regulators do. The pile sorts documented thirteen other categories relevant to the fishers with considerable variation found among the ports. Many categories revolve around fishing area, broad categories of target species and time and distance from port. Other categories that appeared included professionalism, processing possibilities on board, a specialized fishery, quota ownership, taxation, cooperation, working alone on board, oil consumption, environmental impact, fishing intensity, production, and treatment by management. Conflicts between gear groups, local port rules, and fuel costs were important determinates of categories in addition to national or EU fishery regulation. In general, fishers' prefer categories that are large enough to allow seasonal flexibility while at the being precise enough to appreciate their ways of working. For example, coastal fisheries exhibit a preference for flexible gear categories over species categories (Jacobsen et al. 2009).

\section{Conclusion}

Both global and European experiences with MSMF suggests that the management of such fisheries is a dynamic process in which management institutions will need to shift constantly in the face of changing ecological and bio-economic realities. How, within these kinds of SES, can resilience be understood and improved? DGMARE's current suggestions for reforming the CFP (CEC 2009) suggests that the answer is 'getting the 
incentives right'. When institutions recognise the norms and strategies of actors and use them as a way to build toward the common good then these institutions are more resilient. This is the critical insight about resilience that agent-based theories offer.

A communication-based approach provides other sorts of diagnostics for improving SES resilience. One of the sets of boundary objects we examined increased communicative resilience because it provided a focus of discussion, but did so by avoiding the discussion of specific rule conditions. The other set dealt directly with rule conditions and decreased communicative resilience by creating different sets of categories that limited the raising of validity claims because only a sub-set of categories could be effectively referenced.

For recovery plans, all four of the main players are in basic agreement. Recovery plans are needed and they should lead to LTMP based on harvest control rules for the species involved. The key role the plans played was to create a platform for different stakeholders to work out a common strategic goal in the midst of their many differences. Recovery plans were particularly important in the early development of the RACs as multi-stakeholder management institutions (Wilson 2009b). The abstraction of the discussion of recovery plans as broad strategies rather than specific rules requiring defined rule conditions was critical for this. They gave the RACs a way to develop a shared lifeworld without having to commit to specifics, this reduced each groups need to interact strategically.

The definitions of fisheries, fleets and métiers are boundary objects that are much more directly involved in more precise needs for accountability. The discussions were always already rooted in the definitions of fisheries and métiers found either in the DCF, in individual effort control regulations or allocation models. This made the discussion of complexity effectively impossible, even discussions among scientists and managers came to an impasse as DGMARE's need for optimizing mixed fishery models for allocation led to placing demands on scientists they were not ready to meet. Raising the broader issues of concern to the industry and ENGOs was even less possible. The growing narrowness of definitions of fleets and métiers in management was seen as a very serious problem in all of the fishing ports. They have truncated discussion of actual fishing operations while creating incentives and licensing regulations that directly inhibit fishers' ability to change how, where and for what they fish. This is the clearest link in the case studies between communicative resilience - the ability to raise issues requiring rich communications - and the overall resilience of the SES, which depends on adaptive flexibility in respect to the environment. It also illustrates the complementarity of the agent-based and communicative approaches: the communicative failure meant an inability to discuss what it meant to "get the incentives right".

One interesting aspect of comparing the regulatory categories with the fishers' categories revealed in the pile sorts is the concept of decomposable systems. Simon (1962) argued that decomposability is a more common characteristic of complex systems than one would presuppose because of limits on the how many subsystems can simultaneously interact. Furthermore, and this is the point emphasised by Ostrom (2007), nearly decomposable systems are also much easier for us to understand. Ostrom (2007) therefore argues that we need to use tools to decompose SES in order to arrive at effective and well contextualised diagnoses of complex problems. A corollary of this is a temptation when creating boundary objects to create decompositions that are driven more by bureaucratic logic and the needs of easy monitoring than by 
the categories that best reflect conditions on the ground. The end result is a reification of imposed categories that not only oversimplify the local situation but actually change the local fleets to reflect the imposed and now rigid categories.

Hence a key issue revealed by this linkage of CST with boundary objects is how to make accountability effective in the midst of complexity. The basic warning is not to seek accountability through the simplification of reality in ways that create black boxes beyond effective questions and caveats. The classic way to approach the question of downward accountability is the development of nested institutions where decisions are made at the lowest feasible level as defined by ecological processes (Ostrom 1990). This is a useful standard approach but it does not answer the question of how to develop boundary objects for effective accountability for which sufficient lifeworld resources are available to handle complexity. CST suggests that these boundary objects must be simple in a specific way: they must allow effective transparency and direct accountability while avoiding limits to lifeworld access that undercut the boundary objects.

One example of such a system is "results-based" fisheries management (Ulrich et al. 2012), which takes various forms but which emphasizes small scale self-management initiatives characterized by simple but rigorous accountability based on demonstration by fishers that specific, measurable limits on ecological impacts have been honoured while not imposing any further rule conditions on fishing operations. The boundary object of interest is a contract that specifies how the fisheries rights holders will demonstrate compliance with limits. The sector management being adopted in New England approaches this form, although requirements for contracts still involve attempts at operational control (NOAA 2009). Similar ideas are being implemented in Australia, Canada and some coastal fisheries in Europe, often in conjunction with transferable access rights.

Communicative and strategic actions within institutions are linked, but each has its own logic. Where this linkage is clearest is in the need to develop science policy boundary objects that are transparent and allow effective rule conditions. SES resilience is as much a function of what we have called communicative resilience as it is of strategic action in response to the right incentives. The analysis presented here suggests that considering both types of action, and the systems for objectivity/transparency and accountability that lubricate them, may allow us to get a fuller and more systematic picture of resilience within complex SES.

\section{Endnotes}

"The term "power" is the translation found in Habermas (1987) for what we think is more clearly expressed as "authority" as Habermas links the concept to offices.

${ }^{\mathrm{b}}$ Since this research was carried out the European Parliament has been given a "codecision" making role in fisheries.

'This is not a realistic desire. ICES' independence is protected by the fact that it also provides advice to Norway, Russia and Iceland with whom the EU negotiates over shared stocks. These countries would strongly resist the EU replacing ICES with another source of official advice. 


\section{Authors' contributions}

All authors contributed to the field work, contributed text, read and approved the final manuscript.

\section{Acknowledgements}

The research presented here resulted from both field work and discussions within three EU Framework Programme research projects: The $6^{\text {th }}$ Frameworks supported Understanding the Mechanisms of Stock Recovery (UNCOVER) Project no. 022717; A Framework for Fleet and Area Based Fisheries Management (AFRAME) Project no. 044168; and the $7^{\text {th }}$ Framework supported Judgement and Knowledge in Fisheries Involving Stakeholders (JAKFISH) contract no. 212969 This work does not reflect the Commission's views and in no way anticipates its future policy in this area.

\section{Received: 17 October 2012 Accepted: 24 October 2012}

\section{Published: 1 January 2013}

\section{References}

Adger, WN. 2000. Social and ecological resilience: are they related? Progress in Human Geography 24(3): 347-364.

Armitage, D. 2005. >Adaptive capacity and community-based natural resource management. Environmental Management 35(6): 703-715.

Berkes, F, J Colding, and C Folke. 2003. Introduction. In Navigating Social-Ecological Systems: Building Resilience for Complexity and Change, ed. F Berkes, J Colding, and C Folke. Cambridge: Cambridge University Press.

Branch, TA, and R Hilborn. 2008. Matching catches to quotas in a multispecies trawl fishery: targeting and avoidance behavior under individual transferable quotas. Canadian Journal of Fisheries and Aquatic Science 65: 1435-1446.

Brown, S. 1980. Political Subjectivity: Applications of Q Methodology in Political Science. New Haven: Yale University Press.

Caddy, JF, and DJ Agnew. 2004. An overview of recent global experience with recovery plans for depleted marine resources and suggested guidelines for recovery planning. Reviews in Fish Biology and Fisheries 14: 43-112.

Carpenter, SR, BH Walker, JM Anderies, and N Abel. 2001. From metaphor to measurement: resilience of what to what? Ecosystems 4: 765-781.

Cash, D, W Clark, F Alcock, N Dickson, N Eckley, and J Jaager. 2002. Saliency, credibility, legitimacy and boundaries: linking research, assessment and decision making. In School of Government, ed. JF Kennedy. Harvard University Faculty Research Working Paper. Series RWP02-046.

CEC. 2009. GREEN PAPER: Reform of the Common Fisheries Policy. Brussels: DG MARE.

Coxon, APM. 1999. Sorting Data: Collection and Analysis. Thousand Oaks CA: Sage Publications.

DC Wilson. 2009a. The Paradoxes of Transparency: Science and the Ecosystem Approach to Fisheries Management in Europe. Amsterdam: University of Amsterdam Press.

Farnell, J. 2003. Reform of the CFP and its implications for scientific advice and research. Presentation at European Fisheries and Aquaculture Research Organisation Meeting. Rhodes: 4 June 2003.

Folke, C. 2006. Resilience: The emergence of a perspective for social-ecological systems analyses. Global Environmental Change 16: 253-267.

Gunderson, LH, and CS Holling. 2002. Panarchy: understanding transformations in human and natural systems. Washington: Island Press.

Habermas, J. 1987. The Theory of Communicative Action: Volume II Lifeworld and System: A Critique of Functionalist Reasoning. Boston: Beacon.

Habermas, J. 1991. The Philosophical Discourse of Modernity: Twelve Lectures. Cambridge MA: MIT Press.

Hahn, T, P Olsson, C Folke, and K Johansson. 2006. Building knowledge generation and organizational innovations: the role of a bridging organization for adaptive comanagement of a wetland landscape around Kristianstad, Sweden. Human Ecology 34: 573-592.

Hannesson, R. 2004. The Privatization of the Oceans. Cambridge: the MIT Press.

Heritage, J. 1984. Garfinkel and Ethnomethodology. Cambridge: Polity Press.

Holland, JH. 1992. Adaptation in Natural and Artificial Systems. Cambridge: MIT Press.

ICES. 2003. ACFM Annual Report. Denmark: Copenhagen.

Jacobsen, RB, D Damalas, A Delaney, and DCK Wilson. 2009. Stakeholder perceptions of groups of boats. Deliverable 6.1 \& 6.2 of the Improved Fishery Management Through Fleet- and Area-Based Assessments (AFRAME) project. EC Framework Programme 6: Contract no: 044168.

Kapasa, C, I Malasha, and DC Wilson. 2005. Experience Based Knowledge and Fisheries Management in the MweruLuapula System. Annex 11 of the Final Report of the Knowledge in Fisheries Management (KNOWFISH) Project. EU Framework Programme 5. Contract number: ICA4-CT-2001-10033.

Latour, B. 1987. Science in Action. Cambridge: Harvard University Press.

Low, B, E Ostrom, C Simon, and J Wilson. 2003. Redundancy and diversity: do they influence optimal management? In Navigating Social-Ecological Systems: Building Resilience for Complexity and Change, ed. F Berkes, J Colding, and C Folke, 83-114. Cambridge: Cambridge University Press.

Miller, JH, and SE Page. 2007. Complex Adaptive Systems: An Introduction to Computational Models of Social Life. Princeton NJ: Princeton University Press.

Murray, G, T Johnson, BJ McCay, M Danko, K St, and ST Martin. 2010. Creeping enclosure, cumulative effects and the marine commons. International Journal of the Commons 4(1): 367-389.

Nagaski, F, and S Chikuni. 1989. Management of multispecies resources and multi-gear fisheries. FAO Fisheries Technical Paper/305. http://www.fao.org.

National Oceanographic and Atmospheric Administration (NOAA). 2009. NOAA Fisheries Service Fact Sheet. Commercial Fisheries News. Special Supplement • August.

Norberg, J, and GS Cumming (eds.). 2008. Complexity Theory for a Sustainable Future. New York: Columbia University Press.

Ostrom, E. 1990. Governing the Commons. New York: Cambridge University Press,

Ostrom, E. 2005. Understanding Institutional Diversity Princeton. Princeton: Princeton University Press. 
Ostrom, E. 2007. A diagnostic approach for going beyond panaceas. Proceedings of the National Academy of Sciences 104(39): 15181-15187.

Ostrom, E, R Gardner, and J Walker. 1994. Rules, Games, and Common Pool Resources. Ann Arbor: The University of Michigan Press.

Sanchirico, JN, D Holland, K Quigley, and M Fina. 2005. Catch-Quota Balancing in Multispecies Individual Fishing Quotas. Resources for the Future, 05-54. Discussion Paper.

Scott, MB, and SM Lyman. 1968. Accounts. American Sociological Review 33: 46-62.

Simon, HA. 1962. The Architecture of Complexity. Proceedings of the American Philosophical Society 106(6): 467-482. Dec. 12, 1962

Ulrich, Clara, CK Douglas, J Wilson, Rasmus Nielsen, Francois Bastardie, AR Stuart, SA Bo, and RE Ole. 2012. Challenges and opportunities for fleet- and métier-based approaches for fisheries management under the European Common Fishery Policy. Ocean and Coastal Management. Maritime Studies: doi:10.1016/j.ocecoaman. In press - accepted manuscript.

Weick, KE. 2001. Making Sense of the Organization. Malden MA: Blackwell Publishing.

White, S. 1988. The Recent Work of Jurgen Habermas: Reason, Justice and Modernity. Cambridge: The Cambridge University Press.

Wilson, DC. 1998. Markets, networks, and risk: an analysis of labor remuneration in the lake Victoria fishing industry. Sociological Forum 13(3): 425-456.

Wilson, J. 2002. "Scientific uncertainty, complex systems, and the design of common-pool institutions". In The Drama of the Commons, ed. E Ostrom, T Dietz, N Dolsak, PC Stern, S Stonich, and EU Webe, 327-359. Washington: National Academies Press.

Wilson, DC. 2009b. Stakeholder Participation in Recovery Plans. Deliverable No. 30 of the Understanding the Mechanisms of Stock Recovery (UNCOVER) Project. EU 6th Framework Project No 022717 (SSP 8).

Wilson, DCK. 2010a. Considering critical dualism: a response to Fikret Berkes. MAST 9(1): 51-54.

Wilson, DCK. 2010b. Network Structure and Agreement about Science: Applications to Results Based Management. ICES Annual Science Conference. Session P Reversing the burden of proof: results based management of fisheries. Nantes.

Wilson, DC, and S Jentoft. 1998. "Structure, agency and embeddedness: sociological approaches to fisheries management institutions". In Alternative Management Systems, ed. D Symes, 63-72. Oxford: Blackwell Science.

Wilson, DC, JR Nielsen, and P Degnbol. 2003. Conflict and scale: a defense of community approaches in fisheries management" Chapter 11. In The Fisheries Co-management Experience: Accomplishments, Challenges and Prospects, ed. DC Wilson, JR Nielsen, and P Degnbol. Dordrecht: Kluwer Academic Publishers.

Yagi, N. 2001. Draft Country Note on Fisheries Management Systems - Japan. Japan: OECD. Available: http://www.oecd. org/dataoecd/10/46/34429748.pdf.

doi:10.1186/2212-9790-12-1

Cite this article as: Wilson and Jacobsen: Analyzing resilience with communicative systems theory an example

from European fisheries. Maritime Studies 2013 12:1.

\section{Submit your manuscript to a SpringerOpen ${ }^{\circ}$ journal and benefit from:}

- Convenient online submission

- Rigorous peer review

- Immediate publication on acceptance

- Open access: articles freely available online

- High visibility within the field

- Retaining the copyright to your article

Submit your next manuscript at $\boldsymbol{\nabla}$ springeropen.com 